\title{
Love, desire, and the suppression of thoughts of romantic alternatives ${ }^{2}$ Gian C. Gonzaga ${ }^{\mathrm{a}, \mathrm{b}, *}$, Martie G. Haselton ${ }^{\mathrm{b}}$, Julie Smurda ${ }^{\mathrm{b}}$, Mari sian Davies ${ }^{\mathrm{b}}$, Joshua C. Poore ${ }^{\mathrm{b}}$ \\ a eHarmony Labs, Pasadena, CA 91101, USA \\ ${ }^{\mathrm{b}}$ University of California, Los Angeles, CA, USA
}

Initial receipt 30 July 2007; final revision received 13 November 2007

\begin{abstract}
Across human societies, people form long-term romantic bonds that can last a lifetime. Many theorists have proposed that the emotion love plays a causal role in maintaining these bonds, but no work to date has tested this hypothesis directly. In this study, we predicted that feeling love for a romantic partner would facilitate suppressing thoughts of attractive alternative mates. We used a relived emotion task to induce love or sexual desire for a romantic partner and asked participants to suppress thoughts of an attractive alternative. After suppression, participants in the love condition reported fewer thoughts of the attractive alternative and accurately recalled fewer attractiveness-related details about the alternative than those in the desire condition. Reports of love, but not sexual desire, predicted greater commitment to the current partner during the study. These results suggest that love serves a function distinct from desire and that love can operate as a commitment device.
\end{abstract}

(C) 2008 Elsevier Inc. All rights reserved.

Keywords: Commitment; Love; Intimate Relationships; Attractive Alternatives

\section{Love, desire, and the suppression of thoughts of romantic alternatives}

"The heart has its reasons, that reason knows not of." (Blaise Pascal)

Long-term mates, like those in most long-term alliances, face a dilemma. If both partners commit and remain loyal, each benefits from the long-term fitness advantages of the alliance. For example, in traditional societies, cooperative biparental care is linked to greater food resources provided to

\footnotetext{
th The current work was produced, in part, at eHarmony Labs, which is associated with eHarmony.com. Although the current work does not directly test any product of eHarmony.com or use data collected by or at eHarmony. com, its publication may positively impact the financial success of eHarmony.com. Thus, the reader should be aware that the first author is employed by eHarmony and has a significant financial interest in the success of eHarmony.com, the parent organization of eHarmony Labs. The University of California, Los Angeles psychology department has not endorsed eHarmony's commercial selection/matching procedures. Portions of study data were presented at the 2002 Meetings of the Society for Personality and Social Psychology, Los Angeles, California.

* Corresponding author. eHarmony Labs, 888 East Walnut St. 2nd floor, Pasadena, CA 91101, USA.

E-mail address: ggonzaga@eharmony.com (G.C. Gonzaga).
}

offspring during critical periods of development (Marlowe, 2003) and increased offspring survivorship (Hurtado \& Hill, 1992). When partners have cohabitated for longer periods, pregnancies are also less susceptible to life-threatening complications (Robillard et al., 1994). Thus, long term romantic bonds could have profound fitness benefits (for reviews see Gonzaga \& Haselton, in press; Pillsworth \& Haselton, 2006). At the same time, it is in each partner's interest to explore all options to insure that they have found the best partner and, even after establishing a relationship, to consider abandoning their partner if a more attractive alternative becomes available. This produces the commitment problem (Frank 1988, 2001; Hirshleifer, 1987): the benefits of alliances can only be gained through mutual commitment, but mutual commitment requires the foreclosure of other attractive options.

Commitment is further complicated by the human tendency to overvalue immediate benefits relative to longterm gains (Fredrick, Loewenstein, \& O'Donoghue et al., 2003). Benefits to be gained in the future feel less attractive than those we can obtain right now, which is one reason why diets, health resolutions, savings plans, and other attempted commitments fail. In the context of romantic relationships, the long-term bond can be rendered less attractive by the 
temptation of desirable alternative mates. Given this challenge, how do romantic partners stay committed to each other?

\subsection{Love and the commitment problem}

Frank $(1988,2001)$ and Hirshleifer (1987) proposed that emotions, such as vengefulness, outrage, empathy, affection, and love, act as commitment devices by leading people to forego speciously attractive immediate rewards in favor of strategies that yield greater fitness benefits over the longterm. Vengefulness, while immediately costly, can lead to behaviors that shape one's reputation as a person not to be scorned. Empathy, affection, and love can lead to immediate sacrifices that serve to promote long-term relationships. The recurrent experiences of these emotions constitute immediate rewards or punishment that can facilitate commitment in spite of the fact that their ultimate benefits may occur in the distant future (Frank, 1988).

Love, according to the commitment device theory, should help an individual select a mate and to bond exclusively to his or her partner (at least for a time). Indeed, people in love often believe that they have found their one true soul mate in a world of billions of possibilities, and hence, the experience of love appears to help them genuinely foreclose other options. In the current research, we conduct the first experimental examination of the possible relationship between experiences of love and reduced temptation of attractive alternatives.

\subsection{The derogation of alternatives}

In psychology, there is an often-cited literature suggesting that entering relationships leads people to "derogate" their alternatives. These studies have shown that, relative to people not in relationships, those in relationships spend less time visually attending to members of the opposite sex (Miller, 1997), and they rate opposite-sex others as less attractive (Johnson \& Rusbult, 1989; Lydon, Meana, Sepinwall, Richards, \& Mayman, 1999; Simpson, Gangestad, \& Lerma, 1990).

This work is consistent with the hypothesis that love diminishes attraction to alternatives and promotes commitment to a single partner, but for two central reasons, it is far from definitive. First, the conclusions one can draw from these studies are limited because nearly all of them are quasiexperimental in nature, comparing individuals in or out of relationships or dividing participants by level of expressed relationship commitment. A simple and much less interesting alternative explanation for the findings, for example, is that participants involved in relationships realize that it is socially undesirable to state that alternative mates are attractive. In the single study that manipulated commitment (Johnson \& Rusbult, 1989), participants imagined themselves in a hypothetical situation in which they were explicitly instructed - in the low-commitment conditionto actively search for someone else to date, potentially causing participants to report that the alternative was more attractive because of an acquiescence bias. Second, existing research on attraction to alternatives has only examined relationship status and subjective feelings of commitment, rather than directly examining the experience of love. According to the commitment device theory, it is the actual experience of the emotion - the feeling of love-that promotes long-term bonds by acting as an internal incentive system (Frank, 1988).

The central goal of our study was to address these weaknesses by conducting an experimental manipulation of love in the laboratory. To do this, we chose to make use of a subtle psychological phenomenon, the rebound effect.

\subsection{The rebound effect following thought suppression}

Previous work has documented that the active suppression of a thought can lead to an ironic rebound effect (Wegner, Schneider, Carter, \& White, 1987), such that one experiences more of the thought after thought suppression than if one had not attempted to suppress the thought at all. This effect may be especially potent when thoughts are exciting, secretive, and relevant to relationships. For example Wegner and colleagues had participants suppress thoughts about sex and found that the process of suppression led to increase in physiological arousal (i.e., skin conductance level) as compared to suppressing nonexciting thoughts (i.e., about dancing) (Wegner, Shortt, Blake, \& Page, 1990, also see Wegner \& Gold, 1995).

We had individuals suppress thoughts of an attractive alternative while they were induced to feel different emotional states. We predicted that the experience of love, but not other closely-related emotional states, would render the alternative less tempting, and thus, it would reduce or eliminate the rebound effect.

This methodology has three major advantages. First, in addition to eliciting the experience of love, we could induce other closely related emotion states and compare their effects with those of love. We used sexual desire as a comparison. Although romantic love and sexual desire often co-occur, researchers have hypothesized that sexual desire promotes sexual initiation rather than the maintenance of established bonds (Buss, 2003; Diamond, 2003; Fisher, Aron, Mashek, Li, \& Brown, 2002; Gonzaga, Keltner, Londahl, \& Smith, 2001; Gonzaga, Turner, Keltner, Campos, \& Altemus, 2006).

The second advantage of this methodology is that it allowed us to make a strong test of this comparison by eliciting love and sexual desire for the same target, the current romantic partner, and then investigating the divergent effects of these emotional states on participant's ability to suppress thoughts of an attractive alternative. If there are differences in participants' ability to suppress the thought of an attractive alternative under these conditions, we felt we could be confident that the differences are caused by the emotional states themselves.

Finally, the rebound effect is a subtle and nonobvious phenomenon, making it virtually impossible for participants 
to bias their results to confirm our expectations. This is important because, in past studies on the attractiveness of alternatives, participants in relationships may have believed that they should avoid indicating that they found alternatives attractive and biased their responses accordingly.

\section{Method}

\subsection{Participants}

One hundred twenty undergraduate students, 72 women and 48 men [mean age $=19.85$ years; S.D. $=2.53$, Caucasian (38.2\%), Asian (34.2\%), Latino (8.3\%) African American $(2.5 \%)$, others $(15.8 \%)$, from a public university participated for research credit or \$7. All participants were in a monogamous heterosexual dating relationship (mean length, 34.5 months; S.D.=32.1).

\subsection{Materials: photographs}

The authors selected photographs of potential alternatives from public Web sites. Those pictured approximated the age range and ethnic breakdown of the university and were rated as quite attractive by the participants $(M=6.98$, S.D. $=0.70)$.

\subsection{Procedure}

Participants completed the procedure individually with a same-sex experimenter who was blind to the hypotheses of the study. After participants completed consent forms and demographic, relationship, and personality measures, they were led to a table with photographs of attractive oppositesex individuals. They selected the photograph of the individual they found most attractive (i.e., the alternative). The remaining photographs were covered.

Participants reported how attractive they found the alternative on a scale of 1 (least attractive person I have ever seen) to 9 (most attractive person I have ever seen). Then, while alone, participants wrote two 5-min essays on the alternative. The first essay was on why the alternative was attractive. The second essay was on what would constitute a perfect first meeting with the alternative. After writing, each essay participants reported how much they felt 15 different emotions while writing each essay. The photograph was then removed.

\subsubsection{Emotion manipulation}

Participants were randomly assigned to then write two 5min essays about feeling (a) love for their romantic partner (love condition), (b) sexual desire for their romantic partner (desire condition), or (c) their stream of consciousness (control condition). The manipulations were embedded in the instructions that were given to the participant for writing the essays. The suppress instructions and love manipulation appear in brackets after the express instructions and sexual desire manipulation.
"In this next part you will be writing about the time you felt the most sexual desire (love) for your current romantic partner. During this task you should try to think about (it is important that you do not think about) the attractive other individual from the first part of the procedure today. Feel free to express (do the best you can to suppress) any thoughts you have of that individual in the narrative if you chose to.

It is important that we know when or if you do think of the person from the first part of the task. If you do happen to think of the attractive person put a little check in your booklet on the left side of the page next to where you are writing each time you think of them, just like in this example.

As with the last task it is important that you write what comes into your mind as it happens. That is, whatever information is present in your awareness from moment to moment. Your report might include, but is not limited to, descriptions of images, ideas, memories, feelings, fantasies, plans, sensations, observations, daydreams, objects that catch your attention about the writing task. You may also write any other thoughts that come into your mind even if they do not have to do with the task.

When we say sexual desire (love), we mean a specific moment of strong physical or sexual attraction to your romantic partner (when you felt close, connected, and/ or bonded to your romantic partner)."

In the control condition, participants wrote stream of consciousness essays. In the first sentence, they were told to write about whatever came to mind and the final paragraph was deleted. The instructions "if you choose to" at the end of the first paragraph were included only in the express essay instructions.

\subsubsection{Suppression manipulation}

Participants were also randomly assigned to either (a) suppress the thought of the alternative during the third essay and express the thought of the alternative during the fourth essay (rebound condition) or (b) express the thought of the alternative during the third essay and suppress the thought of the alternative during the fourth essay (nonrebound condition). While writing, participants placed a check mark on the page each time they thought of the alternative (Kelly \& Kahn, 1994). The rebound effect was indexed by the number of checkmarks in the express essay after they had suppressed the thought of the alternative (Macrae et al., 1994). Fig. 1 displays the timing and content of the experimental session.

This $3 \times 2$ between-groups design had three emotion conditions (love, sexual desire, control) and two rebound conditions (rebound, nonrebound). Participants reported how much they felt 15 different emotions (including love and desire) during each essay on a scale of 0 (none at all) to 8 (an extreme amount) after each essay. They then 


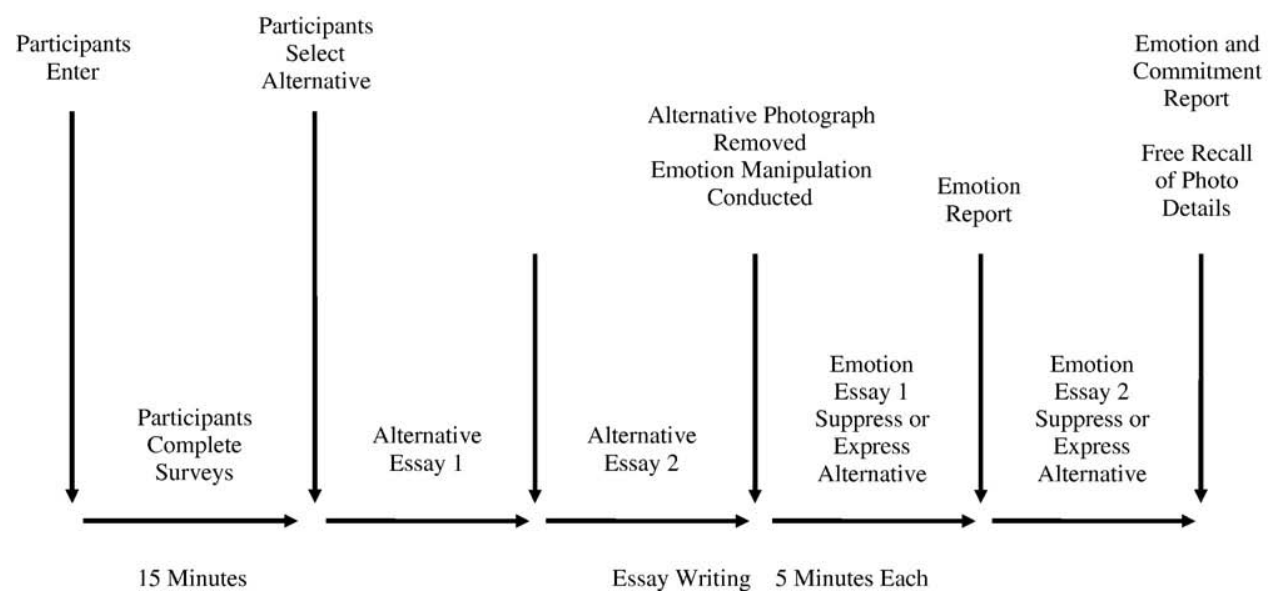

Fig. 1. The timeline and content of the experimental session.

completed the Investment Model Scale (Rusbult, Martz, \& Agnew, 1998), a seven-item measure of commitment $(\alpha=.90)$. After this, participants were given time to recall details about the photograph.

\subsubsection{Coding of the free recall of the photograph responses}

Four judges coded the free-recall memory responses provided by the participants. Two of the four judges coded each response. First, judges coded if the participant correctly recalled each detail. A detail was counted as correct if the judge was able to match the participant's response to some physical detail in the photograph or believed that the response reflected some assessment of the individual in the photograph that $80 \%$ or more of the population would agree with (e.g., the alternative had nice hair or a "hot" body) $(\alpha=.95)$. Next, judges divided the correct responses into two categories: (a) details related to how attractive the individual was (e.g., details about hair, skin, body, muscle tone, and physical fitness level, $\alpha=.90$ ) and (b) details unrelated to how physically attractive the individual was (e.g., details about clothing, jewelry, or the physical location, $\alpha=.88$ ).

\section{Results}

\subsection{Manipulation check}

Participant's ratings of how much love they felt while writing the final two essays were combined. We ran betweensubjects analyses of variance (ANOVAs) to check that reports of love were highest in the love condition. Writing about experiences of love for a romantic partner produced higher levels of love $(M=6.12$, S.D. $=2.25)$ than in the control condition $[M=3.66$, S.D. $=2.21, F(1,78)=24.31, p<.001$, $\left.\eta^{2}=.238\right]$, and desire condition $[M=5.29$, S.D. $=2.10$, $\left.F(1,78)=2.96, p<.05, \eta^{2}=.037\right]$ (both one-tailed tests).

\subsection{Sex differences}

Sex differences in the effects are noted when they occurred. In all other analyses, no sex differences were found.

\subsection{Does love positively relate to subjective commitment?}

We first related reports of love experienced during the procedure to our measure of commitment taken after the end of the study. As a point of comparison, we also related reports of desire to measures of subjective commitment. We predicted commitment from mean reports of love and desire across the third and fourth essays separately for the participants in the love and sexual desire conditions. The control condition was excluded because reports of love and desire were not focused on the romantic partner. Because love and desire were significantly correlated $[r(80)=.48$, $p<.001$ ], we predicted subjective commitment with each emotion independently and also when both were entered simultaneously to show their independent effects. Reports of love positively correlated to subjective commitment using both zero-order correlations $\left[r(79)=.52, p<.001, r^{2}=.27\right]$ and beta weights when love and desire were entered into a regression together $[\beta=.60, t(76), p<.001]$. Reports of desire did not relate to measures of subjective commitment [zeroorder $r(79)=.12$, ns, beta weight $\beta=-.17, t(76)=-1.52, \mathrm{~ns}]$.

\subsection{Does love predict diminished thoughts of attractive others?}

We constructed two measures of thoughts of attractive others. These were the number of thoughts individuals had about the attractive alternative and memory for the attractive alternative at the end of the study. Relative to those in other conditions, we predicted that participants in the love-andrebound condition would have fewer thoughts of the alternative in the express essay and remember less about the alternative at the end of the study.

\subsection{Does suppression while feeling love reduce the rebound of thoughts of an attractive alternative?}

In order to estimate the number of times participants had thoughts of the attractive alternative while writing the essay, we asked them to write checkmarks in the essay each time these thoughts occurred (see instructions above). We used 
the total number of checkmarks as the estimate of the number of thoughts of the alternative that occurred to the participant (e.g., Kelly \& Kahn, 1994). Because the distribution of checkmarks was positively skewed we used a square root transformation to normalize checkmark data (pretransformation skew $=2.48$, posttransformation $=0.52$; Fraley $\&$ Shaver, 1997). In the tables, we present raw numbers for ease of interpretation.

Table 1 shows the mean number of checkmarks by experimental condition and sex of the participant. We first tested to see if love reduced the rebound effect relative to the desire and control condition. This hypothesis held that a significant difference would emerge between the love and desire conditions and the love and control conditions for checkmarks made in express essay in the rebound condition, but not the nonrebound condition. In line with Keppel and Zedeck (1989), we moved directly to our planned comparisons to test these predictions.

Our planned comparisons, tested with ANOVAs, confirmed our hypotheses. As expected, participants in the love condition had fewer thoughts of the alternative than those in the sexual desire condition $\left[F(1,38)=6.33, p<.05, \eta^{2}=.143\right]$ and the control condition $[F(1,38)=17.87, p<.001$, $\left.\eta^{2}=.320\right]$. Participants in the sexual desire condition had marginally fewer thoughts of the alternative than those in the control condition $\left[F(1,38)=2.89, p<.10, \eta^{2}=.071\right]$. The overall emotion effect in the rebound condition for number of thoughts of the alternative in the express essay was significant $\left[F(2,57)=8.56, p<.001, \eta^{2}=.231\right]$.

In the nonrebound condition, there were no significant differences between the three different emotion conditions [overall effect $F(2,57)=1.77$, ns]. The omnibus $3 \times 2$ ANOVA with emotion condition and rebound condition as independent variables showed a significant interaction $[F(2$, $\left.114)=3.42, p<.05, \eta^{2}=.057\right]$ as well as a main effect for emotion condition $\left[F(2,114)=7.12, p<.01, \eta^{2}=.111\right]$.

We then investigated the correlation between thoughts of the alternative and mean reports of love across the third and fourth essays for the participants in the love and sexual desire conditions. Here, we predicted that the more love a participant felt (regardless of emotion condition), the fewer thoughts they would have about the alternative. We related

Table 1

Means and standard deviations of the number of checkmarks by condition and sex

\begin{tabular}{|c|c|c|c|}
\hline & \multicolumn{3}{|c|}{ Emotion condition } \\
\hline & Love & Desire & Control \\
\hline & M (S.D.) & M (S.D.) & M (S.D.) \\
\hline \multicolumn{4}{|c|}{ Rebound condition } \\
\hline Express essay & $0.60(0.88)$ & $2.10(2.69)$ & $3.90(4.48)$ \\
\hline Suppress essay & $0.55(0.94)$ & $1.00(1.26)$ & $3.25(3.06)$ \\
\hline \multicolumn{4}{|c|}{ Non-rebound condition } \\
\hline Express essay & $2.40(2.50)$ & $1.45(1.23)$ & $3.55(3.59)$ \\
\hline Suppress essay & $0.90(1.17)$ & $0.55(1.10)$ & $1.85(2.08)$ \\
\hline
\end{tabular}

The critical comparisons are shown in bold. M, mean. both love and desire, our comparison emotion, to the number of thoughts participants had of the alternative. We also entered both emotions into a regression equation predicting the number of thoughts of the alternative simultaneously to show their independent effects. Love reports related to having fewer thoughts of the attractive alternative, zero-order correlation $[r(80)=-.28, p<.05$, $r^{2}=.078$, beta weight $\left.\beta=-.34, t(77)=-2.77, p<.01\right]$. Reports of desire did not relate to thoughts of the attractive alternatives [zero-order correlation $r(80)=-.04$, $\mathrm{ns}$, beta weight $\beta=.12, t(76)=1.00, \mathrm{~ns}]$. There was one significant sex difference; after controlling for love, desire was positively related to thoughts of the alternative in men $[\beta=.45, t(29)=2.07, p<.05]$ but not women $[\beta=-.01$, $t(45)=-0.07$, ns; difference $Z(78)=2.04, p<.05]$.

\subsection{Does suppression while feeling love reduce memory for attractiveness-related details of the alternative?}

The next set of analyses parallel to those for the checkmark data. Here, we investigated how love and suppression affected memory for details of the attractive alternative. We reasoned that if feeling love and suppressing the thought of the alternative reduced the rebound effect, leading to fewer thoughts, then participants would have a more difficult time remembering details about the alternative. Moreover, we reasoned that if love acts as a commitment device, it would help to suppress relationship-threatening thoughts (i.e., of how attractive an alternative was) more than other types of thoughts. Thus, we predicted that this effect should occur primarily for details about how attractive the alternative was.

Specifically, we predicted that for participants in the rebound condition those in the love condition would remember fewer attractiveness-related details than those in the desire or control conditions. These differences would not occur for attractiveness-unrelated details.

This was the case. We used two planned comparison ANOVAs to test the difference between the love and desire as well as the love and control conditions for attractivenessrelated details. As predicted, there were significant differences between the love $[M=4.58$, S.D. $=2.81]$ and desire conditions $[M=6.42$, S.D. $=2.23, F(1,37)=5.20, p<.05$, $\left.\eta^{2}=.123\right]$, as well as between the love and control conditions $\left[M=6.38\right.$, S.D. $\left.=2.55, F(1,37)=4.38, p<.05, \eta^{2}=.106\right]$. These means are shown in Table 2.

The main effect of emotion for the number of attractiveness-related details occurred only for participants in the rebound condition $\left[F(2,56)=3.32, p<.05, \eta^{2}=.106\right]$. The effect was not significant in the nonrebound condition $[F(2,55)=1.38$, ns $]$. The omnibus ANOVA with rebound condition and emotion condition was not significant $[F(2,111)=1.44$, ns $]$.

There were no significant differences or close to significant differences when testing for differences in the number of attractiveness-unrelated details. As we expected, love decreased participants' ability to remember attractiveness-related details in the rebound condition. 
Table 2

Means and standard deviations of the number of checkmarks by condition and sex

\begin{tabular}{|c|c|c|c|}
\hline & \multicolumn{3}{|c|}{ Emotion condition } \\
\hline & Love & Desire & Control \\
\hline & M (S.D.) & M (S.D.) & M (S.D.) \\
\hline \multicolumn{4}{|l|}{ Rebound condition } \\
\hline Attraction-related & $4.58(2.80)$ & $6.43(2.23)$ & $6.38(2.55)$ \\
\hline Nonattraction-related & $1.89(1.80)$ & $2.73(2.90)$ & $2.08(1.58)$ \\
\hline \multicolumn{4}{|l|}{ Nonrebound condition } \\
\hline Attraction-related & $6.33(3.00)$ & $6.15(2.96)$ & $7.55(2.70)$ \\
\hline Nonattraction-related & $1.44(1.54)$ & $1.70(1.45$ & $1.95(1.38)$ \\
\hline
\end{tabular}

The critical comparisons are shown in bold.

\subsection{Do thoughts of attractive others relate to subjective commitment?}

The final analyses tested the number of thoughts of attractive alternatives related to measures of subjective commitment. Here, we correlated the number of thoughts participants had for the alternative and the number of details (both attractiveness related and attractiveness unrelated) to measures of subjective commitment in the entire sample. There was a significant negative correlation between the number of thoughts of the alternative and measures of subjective commitment $\left[r(119)=-.37, p<.001, r^{2}=.137\right]$. There was also a negative correlation between remembering attractiveness-related details about the alternative and commitment $\left[r(17)=-.20, p<.05, r^{2}=.04\right]$. There was no correlation between remembering attractiveness-unrelated details about the alternative and commitment $[r(117)=.08$, ns]. The difference between the correlations of attractiveness-related details and commitment and attractivenessunrelated details and commitment was significant $[Z(117)=3.02, p<.01]$. There was one significant sex difference: in women, there was a negative correlation between subjective commitment and memory for attractiveness-related details $[r(70)=-.32, p<.01]$ but no correlation in men $[r(47)=.03$, ns, difference $Z(117)=1.86, p<.05]$.

\section{Discussion}

Is love a commitment device? Love does relate to prorelationship behavior and verbal affirmations of affection (Gonzaga et al., 2001). However, to commit absolutely to an intimate relationship, one must close pathways to alternative relationships. Doing this is costly - an individual would not willingly foreclose on alternative relationships if not truly committed to his or her partner. We tested the hypothesis that love is indeed associated with individual costs paid in the service of the relationship, namely, reduced thoughts of alternatives, worse memory of what made the alternative attractive, and hence, reductions in the degree to which alternative mates are considered. We found that love does seem to engage cognitive mechanisms associated with the preservation of the relationship. As predicted, people induced to feel love for their partner were more successful in suppressing thoughts of attractive others: Those in the love condition had fewer thoughts of the alternative relative to the sexual desire and control conditions, but only after participants had attempted to suppress thoughts of the alternative. We did not find this effect when participants were induced to feel the related emotion of sexual desire for their partner, suggesting that quashing mate search might be specific to love. We also found that love, but not desire, related to subjective commitment to the partner at the end of the procedure and thoughts of the alternative, and memory for the alternative negatively related to subjective commitment.

If love is a commitment device, it should insure that an individual both commits to the partner and convincingly communicates commitment to the partner. Past research has shown that romantic partners are sensitive to the behavioral cues of love from their partner (Gonzaga et al., 2001, 2006). The current work is the first to show a causal link between the experience of love and cognitive processes that bolster commitment to a partner within an individual's own mind. Partners should also be sensitive to cues indicating whether mate search is active or suppressed in their partner. For example, individuals in relationships may be sensitive to their partner gazing at or flirting with others, and a partner in love could actively demonstrate that he or she is not tempted by alternatives by forgoing these activities. Investigating this specific phenomenon presents another promising avenue for future research.

Overall, we found few sex differences. One sex difference that emerged was that love did not reduce the number of attractiveness-related details men remembered about an attractive alternative relative to desire and the control condition. This finding is consistent with extensive evidence that men have a greater appetite for sexual variety than do women (Schmitt et al., 2003). Men may therefore be more enticed by attractive alternatives, and this temptation should reduce the impact of our inductions of love among men. Overall, our emotion effects were relatively consistent across both sexes, suggesting that once fully elicited, love and desire serve a similar function in women and men in the long-term relationship setting. This is consistent with parental investment theory (Trivers, 1972), which predicts similarities between the sexes in long-term mating and differences between the sexes primarily in short-term mating (see also Buss \& Schmitt, 1993; Kenrick, Sadalla, Groth, \& Trost, 1990).

\subsection{Limitations of the current studies}

There are limitations to these findings. First, a legitimate question is whether our laboratory manipulation reflects events that occur in the natural world. In a sample of college students, we found that over $33 \%$ had attempted to suppress intrusive thoughts of attractive alternatives. Thus, at least among young adults, suppressing thoughts of attractive others seems to be a common practice (those 
interested in these data may contact the authors for more details). Whether or not people engage in thought suppression as a way of shoring up their relationships, our findings are clearly noteworthy from a theoretical standpoint. They are the first results to demonstrate that love diminishes the temptation of alternatives and to link this phenomenon to subjective commitment.

Second, a question not addressed by our study is whether the effects we have documented are sufficiently strong to maintain commitment in relationships. We do not claim that any single instance of love helps an individual to suppress thoughts of others or that increasing commitment would have a major, longstanding impact on an ongoing relationship. Rather, we believe that repeated instances of love, aggregated over time, help to maintain commitment. This proposal could be tested in future work.

Third, there were strong correlations between love and sexual desire, raising the question of why emotions we claim to be distinct relate so strongly to each other. Diamond $(2003 ; 2004)$ has proposed that love and sexual desire will elicit each other in many but not all circumstances. This elicitation is most likely to occur when a relationship embodies both commitment and reproductive functions. For example, if a partner has qualities that are valuable in both a long-term partner (Buss, 1989; Buss \& Schmitt, 1993) and a sexual partner (Gangestad \& Simpson, 2000; Miller, 2000; Singh, 1993), love and desire should co-occur, and the experiences of love and desire positively correlate. There are also circumstances in which one would not expect these two emotions to be strongly related (e.g., one-night stands, getting support from a partner during a long-term illness, engaging in cooperative child care).

There have been proposals that emotions like love are distinct and relatively independent modules that have evolved to address longstanding evolutionary challenges (Kenrick, 2006; also see Keltner \& Haidt, 2001, for a related view). Other work has shown that love coordinates a number of different physiological, motivational, and behavioral systems to maintain commitment to a romantic partner (Ellis \& Malamuth, 2000; Gonzaga et al., 2001; Gonzaga et al., 2006). In a related vein, for men there is a strong link between short-term mating motives, sexual arousal, and over-perceiving sexual arousal in the faces of attractive women (Maner et al., 2005). Viewing emotions as evolved responses to adaptive challenges is likely to be empirically fruitful.

\subsection{Love, commitment, and thought suppression}

How does the momentary experience of love facilitate the suppression of thoughts of attractive alternatives? Previous work has shown that individuals can successfully suppress particularly threatening or emotionally evocative thoughts (Fraley \& Shaver, 1997; Kelly \& Kahn, 1994; Wegner \& Gold, 1995). These researchers have theorized that some thoughts are so disturbing that they force the individual to invest large amounts of psychological resources to suppress the thought. In time, these individuals practice suppression so much that they are eventually successful (Fraley \& Shaver, 1997).

We believe that it is unlikely that individuals invested the psychological resources necessary to become adept at successfully suppressing thoughts of attractive alternatives, which would relegate the effects of love we observed to a practice effect. It may also be that love facilitates suppression by refocusing attention on the partner, thereby reducing the opportunity to think about the attractive alternative. This explanation seems unlikely considering the differences between the love and sexual desire conditions and the fact that both conditions elicited the emotion in reference to the partner. As sexual desire was targeted towards the partner, it would seemingly focus more of the participant's attention on their partner.

For individuals in long-term relationships they value, thinking of an attractive other is likely emotionally evocative and potentially threatening. Experiencing love-and its promotion of commitment to a partner-may cause an individual to increase their efforts to suppress the thought of the other, leading to successful suppression. This does not preclude the possibility that, in the long term, these thoughts may still rebound. It is unlikely that individuals will permanently foreclose their romantic alternatives-few commitments are truly final, and relationships change over time. Just as burnt bridges can be rebuilt, alternatives foreclosed today may re-emerge, and if love does not persist, the cooperative alliance may dissolve. However, if love is a commitment device, the suppression of these thoughts should remain in place as long as the relationship is valued and elicits the experience of love.

\subsection{Conclusions}

Our studies add to the growing list of work investigating function-specific effects of emotion (Buss, Larsen, Westen, \& Semmelroth et al., 1992; Fessler, Pillsworth, \& Flamson, 2004; Gonzaga et al., 2001; Gonzaga et al., 2006; Lerner \& Keltner, 2001). We supported the hypothesis that love, but not sexual desire, is a commitment device, helping an individual suppress thoughts of an attractive other. Challenges to the relationship are thereby thwarted, and commitment is reinforced. These findings suggest that love is the prescient emotion that helps partners stay committed even when tempted by romantic alternatives.

\section{Acknowledgments}

The authors thank Gian C. Gonzaga, eHarmony Labs and Department of Psychology, University of California, Los Angeles (UCLA). Martie G. Haselton, Department of Communication Studies, Department of Psychology, and The Center for Behavior, Evolution, and Culture, UCLA. Julie Smurda, Mari Sian Davies, \& Joshua C. Poore, Department of Psychology, UCLA. The authors would also like to thank April Bleske, David Buss, Belinda Campos, 
Rob Kurzban, Debra Lieberman, Elizabeth Pillsworth, and Heather Setrakian for comments on previous drafts.

\section{References}

Buss, D. M. (1989). Sex differences in human mate preference: evolutionary hypotheses in 37 cultures. Behavioral and Brain Sciences 12, 1-49.

Buss, D. M. (2003). The Evolution of Desire: Strategies of Human Mating. York: Basic Books; 2003.

Buss, D. M., Larsen, R. J., Westen, D., \& Semmelroth, J. (1992). Sex differences in jealousy: evolution, physiology, and psychology. Psychological Science 3, 251-255.

Buss, D. M., \& Schmitt, D. P. (1993). Sexual strategies theory: An evolutionary perspective on human mating. Psychological Review 100, 204-232.

Diamond, L. M. (2003). What does sexual orientation orient? A biobehavioral model distinguishing romantic love and sexual desire. Psychological Review 110, 173-192.

Diamond, L. M. (2004). Emerging perspectives on distinctions between romantic love and sexual desire. Current Directions in Psychological Science 13, 116-119.

Ellis, B. J., \& Malamuth, N. M. (2000). Love and anger in romantic relationships: a discrete systems model. Journal of Personality 68, 525-556.

Fessler, D. M. T., Pillsworth, E. G., \& Flamson, T. J. (2004). Angry men and disgusted women: an evolutionary approach to the influence of emotions on risk-taking. Organizational Behavior and Human Decision Processes 95, 107-123.

Fisher, H., Aron, A., Mashek, D., Li, H., \& Brown, L. (2002). Defining the brain systems of lust, romantic attraction, and attachment. Archives of Sexual Behavior 31, 413-419.

Fraley, C. R., \& Shaver, P. R. (1997). Adult attachment and the suppression of unwanted thoughts. Journal of Personality and Social Psychology 73, 1080-1091.

Frank, R. H. (1988). Passions within reason: the strategic role of the emotions. New York: Norton; 1988.

Frank, R. H. (2001). Cooperation through emotional commitment. In R. M. Nesse (Ed.), Evaluation and the capacity for commitment (pp. 57-76). New York: Russell Sage; 2001.

Fredrick, S., Loewenstein, G., \& O’Donoghue, T. (2003). Time discounting and time preference: A critical review. In G. Loewenstein, \& D. Read (Eds.), Time and decision: economic and psychological perspectives on intertemporal choice (pp. 13-86). New York: Russell Sage; 2003.

Gangestad, S. W., \& Simpson, J. A. (2000). The evolution of human mating: trade-offs and strategic pluralism. Behavioral and Brain Sciences 23, 204-232.

Gonzaga, G. C., \& Haselton, M. G. (in press). The evolution of love and long-term bonds. To appear in J. Forgas \& J. Fitness (eds.) Social Relationships: Cognitive, Affective, and Motivational Processes (the 10th Sydney Symposium on Social Psychology, NY: Psychology Press.

Gonzaga, G. C., Keltner, D., Londahl, E. A., \& Smith, M. D. (2001). Love and the commitment problem in romantic relations and friendship. Journal of Personality and Social Psychology 81, 247-262.

Gonzaga, G. C., Turner, R. A., Keltner, D., Campos, B. C., \& Altemus, M. (2006). Romantic love and sexual desire in close relationships. Emotion $6,163-179$

Hirshleifer, J. (1987). On emotions as guarantors of threats and promises. In J. Dupre (Ed.), The latest on the best: essays on evolution and optimality (pp. 307-326). Cambridge, MA: The MIT Press; 1987.

Hurtado, A. M., \& Hill, K. R. (1992). Paternal effect on offspring survivorship among Ache and Hiwi hunter-gatherers: implications for modeling pair-bonding stability. In: Hewlett BW, editor. Father-child relations: cultural and biosocial contexts. Hawthorne, NY: Aldine de Gruyter; 1992, . p. 31-55.

Johnson, D. J., \& Rusbult, C. E. (1989). Resisting temptation: devaluation of alternative partners as a means of maintaining commitment in close relationships. Journal of Personality and Social Psychology 57, 967-980.

Kelly, A. E., \& Kahn, J. H. (1994). Effects of suppression of personal intrusive thoughts. Journal of Personality and Social Psychology 66, 998-1006.

Keltner, D., \& Haidt, J. (2001). Social functions of emotions. In T. J. Mayne, \& G. A. Bonanno (Eds.), Emotions: current issues and future directions (pp. 192-213). New York: Guilford Press; 2001.

Kenrick, D. T. (2006). A dynamical evolutionary view of love. In R. J. Sternberg, \& K. Weis (Eds.), Psychology of love. (2nd ed., pp. 15-34). New Haven: Yale University Press; 2006.

Kenrick, D. T., Sadalla, E. K., Groth, G., \& Trost, M. R. (1990). Evolution, traits, and the stages of human courtship: qualifying the parental investment model. Journal of Personality 58, 97-117.

Keppel, G., \& Zedeck, S. (1989). Data Analysis for Research Designs: Analysis of Variance and Multiple Regression/Correlation Approaches. New York: W. H. Freeman; 1989.

Lerner, J. S., \& Keltner, D. (2001). Fear, anger, and risk. Journal of Personality and Social Psychology 81, 146-159.

Lydon, J. E., Meana, M., Sepinwall, D., Richards, N., \& Mayman, S. (1999). The commitment calibration hypothesis: when to people devalue attractive alternatives? Personality and Social Psychology Bulletin 25, $152-161$

Maner, J. K., Kenrick, D. T., Becker, D. V., Robertson, T. E., Hofer, B., Neuberg, S. L., Delton, A. W., Butner, J., \& Schaller, M. (2005). Functional projection: how fundamental social motives can bias interpersonal perception. Journal of Personality and Social Psychology $88,63-78$.

Marlowe, F. W. (2003). A critical period for provisioning by Hadza men: implications for pair bonding. Evolution and Human Behavior 24(3), $217-229$

Miller, G. F. (2000). The Mating Mind. New York: Doubleday; 2000.

Miller, R. S. (1997). Inattentive and contented: relationship commitment and attention to alternatives. Journal of Personality and Social Psychology $73,758-766$.

Pillsworth, E. G., \& Haselton, M. G. (2006). Women's sexual strategies: the evolution of long-term bonds and extra-pair sex. Annual Review of Sex Research .

Robillard, P. Y., Hulsey, T. C., Perianin, J., Janky, E., Miri, E. H., \& Papiernik, E. (1994). Association of pregnancy-induced hypertension with duration of sexual cohabitation before conception. Lancet 344 (8928), 973-975.

Rusbult, C. E., Martz, J. M., \& Agnew, C. R. (1998). The investment model scale: measuring commitment level, satisfaction level, quality of alternatives, and investment size. Personal Relationships 5, 357-391.

Schmitt, D. P., et al (2003). Universal sex differences in the desire for sexual variety: tests from 52 nations, 6 continents, and 13 islands. Journal of Personality and Social Psychology 85, 85-104.

Simpson, J. A., Gangestad, S. W., \& Lerma, M. (1990). Perception of physical attractiveness: mechanisms involved in the maintenance of romantic relationships. Journal of Personality and Social Psychology 59, 1192-1201.

Singh, D. (1993). Adaptive significance of female physical attractiveness: role of waist-to-hip ratio. Journal of Personality and Social Psychology 65, 293-307.

Trivers, R. L. (1972). Parental investment and sexual selection. In: Campbell BG, editor. Sexual Selection and the Descent of Man. Chicago: Aldine; 1972, . p. 136-179.

Wegner, D. M., \& Gold, D. B. (1995). Fanning old flames: emotional and cognitive effects of suppressing thoughts of a past relationship. Journal of Personality and Social Psychology 68, 782-792.

Wegner, D. M., Schneider, D. J., Carter, S. R. I., \& White, T. L. (1987). Paradoxical effects of thought suppression. Journal of Personality and Social Psychology 53, 5-13.

Wegner, D. M., Shortt, J. W., Blake, A. W., \& Page, M. S. (1990). The suppression of exciting thoughts. Journal of Personality and Social Psychology 58, 409-418. 